\title{
Research
}

\section{Assessing Changes in Fisheries Using Fishers' Knowledge to Generate Long Time Series of Catch Rates: a Case Study from the Red Sea}

\author{
$\underline{\text { Dawit Tesfamichael }}^{1,2}$ Tony J. Pitcher $^{1}$ and $\underline{\text { Daniel Pauly }}^{1}$
}

\begin{abstract}
The data requirements for most quantitative fishery assessment models are extensive, and most of the fisheries in the world lack time series of the required biological and socioeconomic data. Many innovative approaches have been developed to improve data collection for fisheries. We explored the use of data from fishers' interviews to estimate time series of approximate "best" catch rates. A total of 472 standardized interviews were conducted with 423 fishers along the southern Red Sea coast recording the best catch recalled and the change in average catch rates throughout the fishing career of interviewees. The results showed a decline of best catch rates in all fisheries, ranging from $4 \%$ to $10 \%$ per year for more than 50 years. The estimated rates of decline of the typical catch were higher for fishers who started fishing in recent years, suggesting that the resource base is declining, in concordance with other indicators. It is suggested that analysis of approximate data, quickly acquired at low cost from fishers through interviews, can be used to supplement other data-recording systems or used independently to document the changes that have occurred in the resource base over a lifetime of fishing. The results can be used to guide the assessment and management of resources to conserve ecosystems and livelihoods.
\end{abstract}

Key Words: assessment; catch rates; fishers' knowledge; interview; Red Sea; small-scale fishery; time series

\section{INTRODUCTION}

Data needs in fisheries science and management

Fisheries have a major impact on marine ecosystems (Worm et al. 2006), and a proper assessment of the resource and users will have a crucial role in effective conservation. The most basic and informative data in fisheries are time series of catch and effort (Caddy and Gulland 1983, Pauly and Zeller 2003), from which catch per unit effort (CPUE) is calculated, which can be, when used with caution, an indicator of abundance (Harley et al. 2001). This is why fishery data collection is critical at both local and international levels (Garibaldi 2012). Most fishery data collection systems, however, emphasize industrial fisheries (McCluskey and Lewison 2008). Small-scale fisheries, which account for more than $95 \%$ of the world's fishers and are critical to the socioeconomic life of communities (Berkes et al. 2001, Pauly 2006, Andrew et al. 2007), do not, however, get the attention they deserve. It is also estimated that about a third of the global catch (Chuenpagdee and Pauly 2008) and half of the seafood directly consumed by humans originate from small-scale fisheries (Pauly 2006). In the Red Sea, small-scale fisheries have contributed up to $70 \%$ of the total retained catch since 1950 (Tesfamichael 2012). Thus, a form of fisheries research that takes the small-scale fisheries into full consideration appears to be imperative (Berkes et al. 2001).

\section{Tapping into fishers' memory or knowledge}

Even if information about small-scale, or artisanal, fisheries is not usually readily available in official records, this does not mean that there is no information (Johannes et al. 2000). Notably, information can be acquired from the memory of resource users, which is gaining more attention in fisheries research. However, how this information is best used is still debated (Johannes et al. 2000, Sáenz-Arroyo et al. 2005b, Haggan et al. 2007). Soto (2006) and Hind (2012) reviewed the literature on fishers' knowledge and its acceptance, or lack thereof, within mainstream fisheries research and management. The views on the usefulness of fishers' knowledge vary quite widely: Some think it is "useless" and does not add to fisheries science and management (see Walley 2002); others think it can be useful but difficult to harmonize with fisheries science (Jentoft et al. 1998), or that it can aid fisheries science (Mackinson and Nottestad 1998, Neis et al. 1999); and there are also those who advocate for more weight to be given to fishers' knowledge because biology-orientated mainstream fishery research methods have failed many times (Ludwig 2001, Holm 2003). Most interview-based research with natural resource users so far has been qualitative with emphasis on the socioeconomic dynamics of the communities, a reason used by quantitative fishery researchers to disregard it as inferior to quantitative approaches (Soto 2006). Another major criticism is that it gives little or no attention to the status of the resources exploited in the community in question (Salmi 1998, Pauly 2006, Anadón et al. 2009).

Interview-based methods to acquire quantitative information have been used to try to understand the state of ecosystems in the past (Sáenz-Arroyo et al. 2005a, 2005b, Bunce et al. 2008, LozanoMontes et al. 2008). Fuzzy logic has been applied, in some cases, to standardize and quantify qualitative data collected through interviews (Mackinson 2001, Ainsworth et al. 2008, Moody and Pitcher 2010). Moreover, interview-based approaches have been used for contemporary analyses, e.g., preliminary assessment of the ecological and socioeconomic sustainability of fisheries (Teh et al.2005), or to obtain information on the bycatch that is omitted in landing recording systems (Moore et al. 2010). Also, because different fisher age groups can be interviewed, interview-based methods have been very useful in quantifying cases of the shifting baseline syndrome (Pauly 1995, Sáenz-Arroyo et al. 2005b, Ainsworth et al. 2008, Lozano-Montes et al. 2008). These approaches can be an important source of information and sometimes the only one, e.g., in societies with strong oral traditions.

\section{Methodological issues}

Interview-based methods depend on the cognitive faculty of interviewees and have been used for collecting data over wide areas and periods of time at relatively low cost (Neis et al. 1999, Anadón et al. 2009, Moore et al. 2010). However, interview protocols that are not standardized hinder comparison because estimates 
derived from interviews can be sensitive to the methodology used (Fowler 2009, Moore et al. 2010). The main liability of interviewbased data collection has been its questionable reliability. There are not many studies that have investigated this issue directly, because most fisheries researchers have used interviews mainly to fill in data gaps (Baelde 2003). There are studies, however, that have used interviews simultaneously with other methods to assess fisheries. Some of the researchers, when studying the same fisheries, found similar trends and reached similar or complementary conclusions (e.g., Neis et al. 1999, Otero et al. 2005, Begossi 2008, Lozano-Montes et al. 2008). However, others generated mixed results; that is, there were similarities in some indices and not in others (Ainsworth and Pitcher 2005, Daw 2008, Silvano and Valbo-Jørgensen 2008). Besides empirical fisheries studies, there is more evidence of this phenomenon from cognitive psychology, which confirms that although it is difficult to recall individual events that are routine, unique events can be recalled straightforwardly (Bradburn et al. 1987). These vivid memories, referred to as a "flashbulb," are characterized by having high personal importance (Rubin and Kozin 1984). Fishers recall and describe, as also observed in this research, their "best catch ever" vividly and with pride, similar to the best trophy kill of hunters.

Eliciting unique memories requires work. During pilot interviews, fishers were asked a direct question: "What is your best catch ever?" Almost always, their answer was that "the catch varies as the sea gives" or words to this effect. Later, the same question was weaved into a story: "When you go to the sea to fish you do not always catch the same amount, when you are lucky you catch a lot, and other days you may come back empty and lose money. But if you look back, there must be one day where you caught a lot of fish and came back happy." The latter approach almost always caused a change in the interviewees' countenance. They smiled and started telling their stories in vivid detail and did not want to be interrupted. They recalled the time of day they departed, the state of the sea, temperature, the phase of the moon, the names of all the crew members, how long it took them to pull the net or that they required help from other boats, how tired they were pulling their lines, and so forth. At the end of their stories, they were able to estimate the size of their best catch. Thus, giving appropriate cues helps interviewees to recall memories; location, e.g., you came back quickly, and social events, e.g., all the crew were happy and singing, are good cues (Bradburn et al. 1987).

One of the main challenges to interview-based data collection is the reliability of the information gathered. There are two main kinds of biases (Daw 2010): retrospective bias and a tendency to distort facts because of their perceived potential to affect management or policy (Bradburn et al. 1987, Henry et al. 1994, O'Donnell et al. 2010). Research on the accuracy of people's memory has been conducted mainly by psychologists, who have widely debated the use of retrospective methods to reconstruct past events (Henry et al. 1994). However, empirical research on the related bias is not common even in psychology (Koriat and Goldsmith 2000). In a paper evaluating retrospective methods for comparing past data collected through interviews, i.e., retrospective, and data measured independently in the past, such as archival material, i.e., prospective, Henry et al. (1994) reported that cognitive and motivational factors may lead to inefficient and inaccurate processing of past information. They also found that for variables measured along dimensional scales, i.e., quantitatively measurable variables, there was a strong correlation between the retrospective and prospective data; whereas the correlation was poor for psychosocial variables, i.e., subjective psychological states. Even for strongly correlated quantitative variables, accuracy was poor, mainly because of a systematic tendency by the interviewees to shift their estimates toward desirable states. However, this bias was not the result of a memory recall error, because contemporaneous reports also showed similar bias.

Thus, interviews can be used in fisheries research to track relative changes, whereas the utmost caution is required when absolute values are in play. However, the values gathered through interviews should be checked against independently measured parameters, which can be used as an anchor to translate the interview data to an absolute scale, as is done, for example, when estimating unreported fisheries catches from anecdotes (Pitcher et al. 2002, Tesfamichael and Pitcher 2007).

There are few studies in fisheries that have quantitatively assessed the accuracy of fishers' interview data. O'Donnell et al. (2010) examined the possible effects of interview accuracy in conservation assessment by running two scenarios: one where the interview data was assumed to be accurate and the other where the fishers were assumed to overestimate or exaggerate their responses. They found that accuracy can be a serious problem in the assessment of the resource and suggested that the accuracy assumption built into the interview data must be explicitly stated. Otero et al. (2005) compared catch rates and total catch from interviews with official reports. They found that the two sources correlated positively, but that the total catch from interviews was higher than the official one, which, they suggested, was the result of unreported catch not being included in the official statistics. In this case, interviews gave more accurate results than official statistics. Daw et al. (2011) compared CPUE data from interviews, official reports, and underwater visual censuses and found disagreement among them. They concluded that each data source had its own limitations and biases, and that none could be taken at face value. Even the most independent abundance measurement, the underwater visual census, had sampling problems, e.g., depth limitation, and there was also a mismatch between the area sampled by the visual census and the fishing grounds (Daw 2008, Daw et al. 2011). O’Donnell et al. (2012) compared CPUE data from interviews, logbooks, and official catch landing records. Although they found that all sources showed similar trends, absolute CPUE values from interviews were higher and more variable. Again, the higher CPUE could be attributable to either the inclusion of unreported catch in the interview reports, similar to Otero et al. (2005), or exaggeration of their catch by the interviewees. Agreement of interview data was found to improve with the reported fishing experience of interviewees (Ainsworth and Pitcher 2005).

We used interviews to systematically collect quantitative catch and effort data in part of the Red Sea, which were then turned into time series. For comparison purposes, the same procedure was used in three countries and six fisheries, which were identified by the type of gear. The analysis was used to (1) quantify the change in catch rate by interviewing fishers recruited to fishing at different times and using the best catch they recalled having made; and (2) quantify changes in the typical, i.e., average, catch rates 
of fishers between the time they started fishing and 2007, when the interviews were held. For the latter analysis, we further applied a unique method to calculate the rate of change in catch rate to examine the major changes in the fisheries. Our focus and contribution is on systematic collection of data, i.e., knowledge, through interviews and analyzing the data in such a way that the information can aid, i.e., inform, management and conservation efforts side by side with other traditional quantitative fisheries methods. Additionally, we present theoretical considerations from different fields, i.e., fisheries biology, sociology, and cognitive psychology, and empirical examples of the use of interviews in fishery research data collection. In addition, the lessons learned on interview-based procedures to collect quantitative time series catch and effort data are documented.

\section{METHODS}

\section{Study area}

The research was carried out in fishing communities in three countries in the southern Red Sea: Eritrea, Sudan, and Yemen (Fig. 1). In Eritrea, a wide range of fishing villages, from the main port city of Massawa in the north to the Djibouti border in the south, and the villages in Dhalak Kebir Island, were covered. This wide range was possible because extra support for assistance and transportation funding was available. In Sudan, the main port city of Port Sudan, Mohamed Qol and Dungunab in the north, and Suakin in the south were sampled. In Yemen, only the Red Sea coast was sampled; most of the interviews were conducted in the main fishing port of Hodeidah with a few in Al Koka, in the south.

Fig. 1. Map of the Red Sea indicating the areas where interviews were conducted.

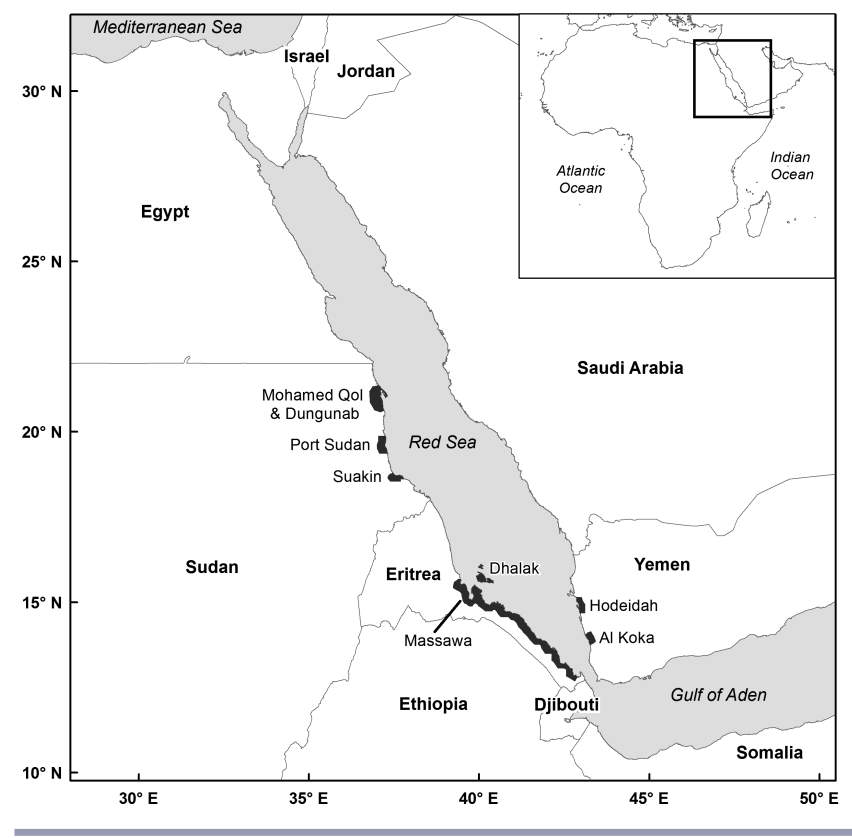

\section{Questionnaire}

A semistructured questionnaire was chosen for the interview because it provided a general framework and also flexibility for the interviewer to probe new ideas as the interview progressed. It also gave a more natural flow of discussion between the interviewer and interviewee (Wengraf 2001). It had three parts: general biodata, which were asked of all interviewees; specific questions, based on the fishing gear they operate; and, finally, catch data (Appendix 1).

\section{Sampling}

A combination of random, snowball, and targeted sampling methods were applied. Potential interviewees were approached, usually at fish landing sites or in their villages, and a brief account of the research and what was expected of them was explained. Also, their consent to be interviewed was obtained before any interview was carried out according to the methodological recommendations of Bunce et al. (2002) and Huntington (2000). Effort was made not to interfere with their operations. For example, no interviews were requested when they were operating fishing gear or landing their catch, the latter is critical given that fish quickly starts to spoil in the hot sun of the Red Sea coast. The best time was after their daily routine activities when fishers were relaxing or mending their nets or during their days off in their villages. When visits were made to the fishing villages, the elders were first approached, and once they gave their approval for the work to continue, fishers were then interviewed. The elders were very helpful in securing the collaboration of fishers for the interviews. Each interview took on average 30 to 45 minutes.

Of all the different gear types, emphasis was given to fisheries with a high contribution to the total catch. The gear selected included gillnet, hook and line, and shark fisheries for Eritrea; hook and line for Sudan; and gillnet and hook and line for Yemen. An effort was made to have a wide age range of fishers in the sampling. It was not easy to find older interviewees, so targeted requests were made for them. For cultural reasons, it was not possible for women to be included in the interviews.

\section{Standardizing data}

Fishers often did not report their catches and efforts in units that could be analyzed and compared directly. For example, catches were given in number of boxes, kilograms, number of fishes, and so forth. The following standardizations were carried out on the raw data: In Eritrea, fish landings were sometimes reported in number of sacks, especially in the past; one sack was measured to be approximately $45 \mathrm{~kg}$ of fish. In Yemen, boxes, locally called banker, were used especially for Indian mackerel, and were equivalent to about $40 \mathrm{~kg}$. Bundles of fishes tied in a rope, called mihkal, were also common in Yemen. It was estimated that a bundle held 5 to $10 \mathrm{~kg}$ of fish, and the midvalue of $7.5 \mathrm{~kg}$ was used for conversions.

Almost none of the shark catch data were provided in total wet, or live, weight (TWW), but as dried fin weight (DFW), dried meat, or wet dressed carcass, i.e., gutted, headed, and all fins removed. Also, irrespective of the nature of the product, either fin or meat, most shark data were given in farasila, a common measurement unit for trade in the Indian Ocean for many centuries, which is equivalent to $16 \mathrm{~kg}$ (Campbell 1993). First, all products were converted from farasila to kilograms. DFW, in kilograms, was 
converted to wet fin weight (WFW) using a regression equation fitted to data from Fong (1999).

$$
\mathrm{WFW}=(0.64 \times \mathrm{DFW})-0.0057 \quad R^{2}=0.99
$$

WFW accounts for about 5\% of the dressed carcass weight (NMFS 1993). This commonly used ratio has been challenged as not sufficiently species specific (Cortes and Neer 2006). Our research aims to look at the shark fishery in general, and there was not enough data to analyze species separately, so the mean ratio had to be used. Once the fin and dressed weight are accounted for, what remains is the head and viscera, which account for $18 \%$ of TWW (Meliane 2003). Substituting the ratios, TWW from DFW, in kilograms, is given as follows:

$$
\mathrm{TWW}=(16.39 \times \mathrm{DFW})-0.15
$$

The other common product of the shark fishery reported by fishers is dried shark meat, which is $60 \%$ of wet weight (Sankat and Mujaffar 2004). The dried shark meat, which is dressed dry weight (DDW), was converted to TWW using the following equation:

$$
\mathrm{TWW}=2.1 \times \mathrm{DDW}
$$

\section{Validation}

The validity of the data obtained from the interviewees was verified at different phases of the research. It started during the interview in which the answers of the interviewees were queried for extreme and unrealistic answers, e.g., a catch too large to be accommodated by a boat. Interviewers were also able to verify the time references that the interviewees used. In most of the interviewed communities, people did not know their ages with any precision because birth certificates did not exist and the culture was predominantly oral. Thus, all references to calendar time made by the interviewees, e.g., the year they had their best catch, were double-checked with major events in the history of the communities, which were anchored in most people's memories (Means and Loftus 1991).

A question with a clear empirical answer was built into the questionnaire to check the validity of responses. The question was "size of largest fish ever caught," and the answer was compared with the maximum size reported in FishBase (Froese and Pauly 2011). Thus, at the end of each interview, the interviewers were able to evaluate the overall reliability of the information that had been provided.

Final validation was done after the data were standardized and entered into a database, using a box plot to identify outliers. Any data point that was less than the first quartile minus 1.5 times the interquartile range or greater than the third quartile plus 1.5 times the interquartile range was considered an outlier and hence dropped from analysis.

$$
X<\mathrm{Q} 1-1.5(\mathrm{Q} 3-\mathrm{Q} 1) \text { or } \mathrm{Q} 3+1.5(\mathrm{Q} 3-\mathrm{Q} 1)<X
$$

\section{Data fitting}

An exponential function was fitted to the best CPUE fishers recalled ever having experienced. An exponential function was selected because the resulting slopes, i.e., instantaneous rates of change, can be compared among different fisheries irrespective of the actual, i.e., scale, value of the catch. In addition, an exponential function, unlike a linear one, does not cross the $\mathrm{x}$ axis, which is realistic; i.e., there cannot be a negative CPUE (Silvert 1981). The equation that fulfills these criteria is as follows:

$$
f(x)=c \times e^{r x}
$$

where $x$ is year, $c$ is a constant, and $r$ is the instantaneous CPUE change rate.

Besides the best catch, fishers were also asked to compare their average, i.e., typical, catch rates between the year they started fishing and 2007 to examine changes in the ratio of catch rates since the fishers were recruited into fishing. Regression analysis was carried out between the ratios and the year the fishers started fishing. The comparison of ratios was enabled by annualizing the ratios, i.e., re-expressing the ratios after normalizing for years fishing. Segmented regression was carried out on the normalized data.

\section{RESULTS}

In total, 472 samples, i.e., interview units, were collected from 423 different fishers, ranging from 12 to 83 years and with fishing experience of 1 to 65 years. Effort was made to obtain a relatively good representation of all age groups; however, the oldest age group $(>61)$ was difficult to sample, especially in Eritrea and Yemen. In Yemen, the youngest age group $(<30)$ was better represented in the sample than the other age groups (Fig. 2). The middle age groups (31-45 and 46-60) were well represented in all countries.

Fig. 2. Age frequency distribution of interviewees by country.

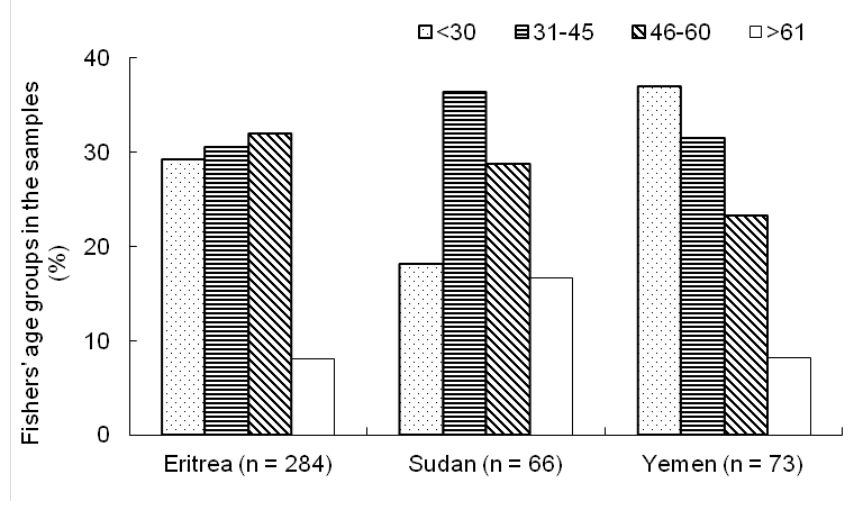

The analysis of the best CPUE fishers recalled was carried out by gear type because gear characterizes the fisheries very well; there is more similarity in terms of the operation within a fishery of the same gear type (Tesfamichael 2001). They all showed decline in CPUE (Fig. 3) in the range of $3.6 \%$ to $10.3 \%$ per year, for Sudanese hook-and-line fishery and Eritrean shark fishery, respectively. The other fisheries in terms of CPUE decline were Yemeni gillnet (4.3\%), Eritrean hook and line (6.6\%), Eritrean gillnet $(7.1 \%)$, and Yemeni hook and line $(8.8 \%)$. 
Fig. 3. Change in best CPUE fishers recalled for (a) Eritrean gillnet, (b) Eritrean hook and line, (c) Eritrean shark, (d) Sudanese hook and line, (e) Yemeni gillnet, and (f) Yemeni hook and line; note that axes have different scales.
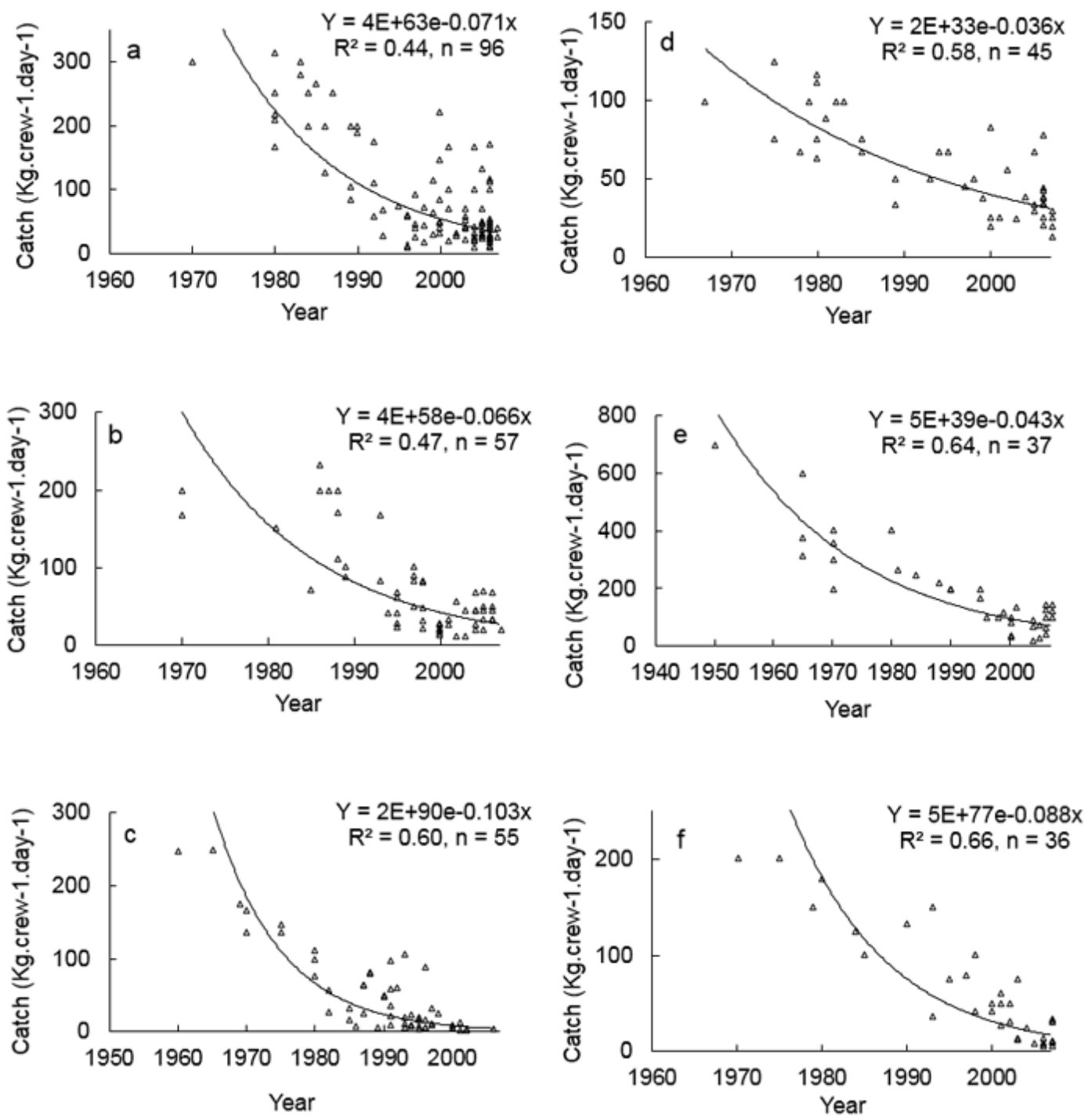

The ratio of typical, i.e., average, CPUE from the time a fisher commenced to that of the year 2007, when the interviews were held, exhibited wide ranges, i.e., 1.17 to 8 for Eritrea and 1.6 to 25 for Yemen (Fig. 4). The declining functions indicate that fishers who started fishing earlier have seen the average catch rate decline more than the fishers who began recently. The analyses in Figure 4 do not account for the number of years the fishers have been fishing, so when they are divided by the number of years the fishers have been fishing, this yields the annual rate at which the typical CPUE is changing (Fig. 5), which confirms that the decline in CPUE has accelerated in recent years. Segmented regression was applied to the data in Figure 5 because there were clear demarcations in the data sets and fitting only one function resulted in a bad fit. To compare the one- and two-segment fitting and to test if there was any statistically significant difference between them, an $\mathrm{F}$ test was carried out on the sum of squares of the residuals (SSR). The results showed that there was significant difference (Table 1). The regression results showed that the decline in CPUE has accelerated in recent years. The break points were determined by the least SSR, which were at 1995 and 1997 for Eritrea and Yemen, respectively. To check if the break points were statistically significant compared with the neighboring years, an F test was carried out. In both cases, Eritrea and Yemen (Fig. 5), the tests showed that they were not significant. Nevertheless, the years with the least SSR were chosen. For Eritrea, the least SSR was 0.38 for 1995 followed by 0.44 for 1997; whereas for Yemen 
it was 1.64 for 1997 , followed by 1.75 for 1994 . In both figures, the early portion of the data sets resulted in slopes that were not significantly different from zero, so horizontal lines, which were the averages, were used. However, in the second segments, there were clear increases in the trends.

Table 1. Results of the statistical test comparing the fitting of catch per unit effort change rate data to one segment or two segments.

\begin{tabular}{lccccc}
\hline \hline \multirow{2}{*}{ Statistic } & \multicolumn{2}{c}{ Eritrea (Fig. 5a) } & & \multicolumn{2}{c}{ Yemen (Fig. 5b) } \\
\cline { 2 - 3 } \cline { 5 - 6 } & $\begin{array}{c}\text { One } \\
\text { segment }\end{array}$ & $\begin{array}{c}\text { Two } \\
\text { segments }\end{array}$ & & $\begin{array}{c}\text { One } \\
\text { segment }\end{array}$ & $\begin{array}{c}\text { Two } \\
\text { segments }\end{array}$ \\
\hline SSR & 1.83 & 0.38 & & 2.8 & 1.64 \\
F calculated & 71.79 & - & & 13.16 & - \\
$p$ & $<0.05$ & - & & $<0.05$ & - \\
& $(3.57)$ & & & $(3.56)$ & \\
\hline
\end{tabular}

Fig. 4. Ratio at which the average CPUE changed for interviewees from the year they started fishing, relative to the 2007 CPUE: (a) Eritrea and (b) Yemen.
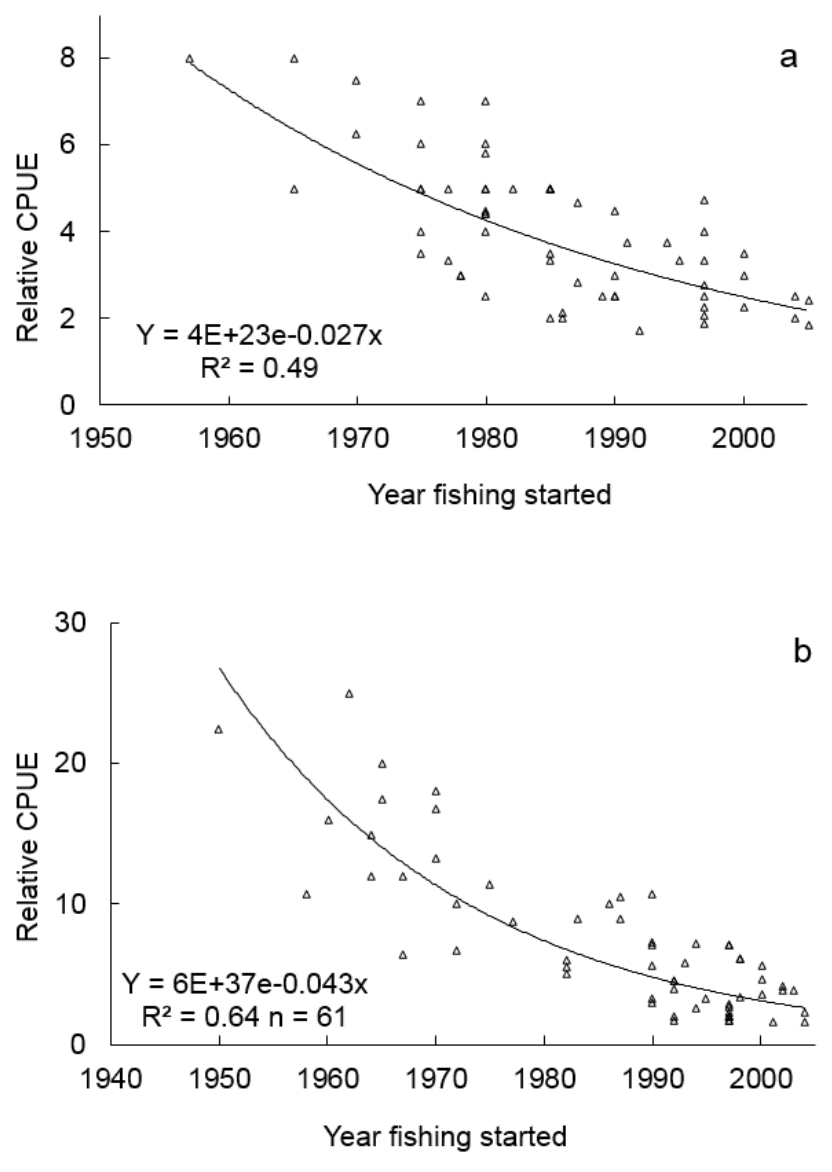

Fig. 5. Annual decline of CPUE over the years of fishing experience of fishers for (a) Eritrea, where the decline increased after independence, and (b) Yemen, where the decline increased after the unification of Yemen and the oil economy boost.
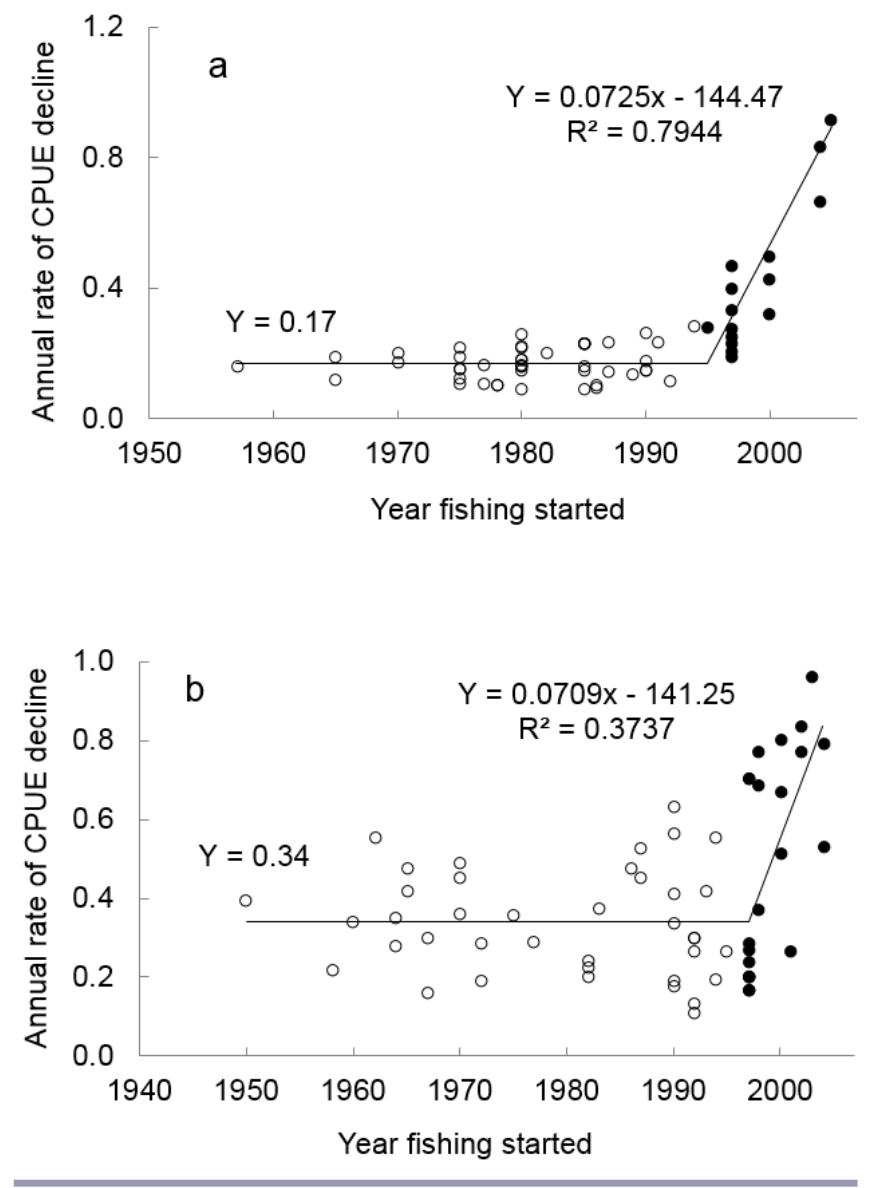

\section{DISCUSSION}

We demonstrated how interview methods can be used to access knowledge lodged in fishers' memory for quantitative analyses. Although the use of fishers' knowledge is getting more attention in fisheries research, how it can be used is still debated (Haggan et al. 2007). One area in which many researchers agree is that a systematic approach during the interviews is crucial. What we found was that asking for an exceptional experience, e.g., the best catch they ever made, and comparing different experiences, e.g., the typical catch at different times, allowed fishers to answer the questions more easily than by posing more general or vague questions, e.g., how much the catch has changed. This confirms similar studies (e.g., Sáenz-Arroyo et al. 2005b, Daw 2008).

The time series trends and the quantitative comparison between different fisheries that they enabled, as we have demonstrated, are informative and useful in fishery assessment and management. For example, knowing the rates at which the different fisheries are declining can be used in prioritizing the attention of the fisheries management system, or they can be used as benchmarks to 
evaluate the effectiveness of management schemes. One major challenge, however, is the use of absolute values rather than relative changes. We do not claim the results to be accurate estimates of the absolute fishery changes over time. However, these values are as informative as other fishery sampling schemes. In some cases, they may be even more accurate because they incorporate the unreported catch that is missed by most datarecording systems (Otero et al. 2005, Anadón et al. 2009). Besides, many quantitative, i.e., noninterview, methods in fisheries are used only to infer relative changes, except for those methods used to set quotas, at which this research did not aim. In terms of patterns, our results are similar to those observed for the Red Sea fisheries using ecosystem modeling (Tesfamichael 2012) and rapid appraisal methods (Tesfamichael and Pitcher 2006). The most striking result is that the rate of CPUE change for sharks based on interviews $(10.3 \%$ per year) is very comparable to the rate calculated from catch and effort data $(11 \%$ per year) (Tesfamichael 2012). This is a good example to demonstrate that an assessment with fewer resources, i.e., interviews in this case, can be as informative as a detailed and resource-intensive approach, i.e., the catch and effort data collection.

Showing a declining function to fit the best catch rates fishers remembered is not a striking finding, because a declining trend is expected for any exploited fishery resource (Beverton and Holt 1957, Hilborn and Walters 1992). However, it was insightful that it could be quantified so straightforwardly from interviews. Out of the 6 fisheries we analyzed, the Eritrean shark fishery exhibited the highest decline rate, $10.3 \%$ per year. There has been a long history of shark fishing in the Red Sea (Ben-Yami 1964). The high global demand for shark fins, combined with the life history of sharks, is taking a toll on the shark population. The lowest decline in the Sudanese fishery (3.6\% per year) is not surprising because the pressure on marine fishes in Sudan is relatively low; more than $90 \%$ of the fish in the country is supplied by freshwater fisheries (FA 2007).

The rapid decline of CPUE for Eritrea and Yemen after 1995 and 1997, respectively (Fig. 5), fits with political stability. After Eritrea's independence in 1991, programs were introduced to develop the fishery, with investment in infrastructure and financial facilities. Similarly for Yemen, the unification of north and south Yemen happened in 1990. At the same time, oil revenues started to increase general investments in the country.

The approach we have described can be useful to complement data gaps for resource assessment; alternatively, it can be used independently for a quick, low-cost assessment of resources without historical data. For effective use of the methodology, a clear definition of the objective and proper preparation, e.g., adequate design of the questionnaire, are important. In addition, an understanding of the culture and communication style of the society to which the interviewees belong is crucial. The scientific community and the system in general can benefit by giving due attention and respect to the knowledge available from fishers and their communities. We conclude with a quote from the late Robert Johannes (1981:vii):

There are hundreds of times as many fishermen today than there are marine biologists, and their forebears were plying their trade and passing on their accumulated knowledge tens of centuries before anyone ever heard of marine biology. What is surprising is how little effort has been made by scientists to search out and record this information.

Responses to this article can be read online at: http://www.ecologyandsociety.org/issues/responses. $\mathrm{php} / 6151$

\begin{abstract}
Acknowledgments:
Our heartfelt thanks go to the fishers who trusted us with their extensive knowledge, stories, and experiences. Our thanks also go to the fishery administrations of Eritrea, Sudan, and Yemen for their invaluable help. The following research assistants deserve special thanks: Aron, Ahmed, Yonathan, and Bokretsion in Eritrea; Khalid and Mohammed in Sudan; and Hesham and Fahad in Yemen. They adopted the interview procedure quickly and made the experience memorable. This research was supported by the Sea Around Us Project, a scientific collaboration between the University of British Columbia and the Pew Charitable Trusts. Extra funding was available from Eritrea's Coastal, Marine \& Island Biodiversity Conservation Project (ECMIB) in the Ministry of Fisheries, the State of Eritrea, and the Natural Science and Engineering Research Council of Canada.
\end{abstract}

\section{LITERATURE CITED}

Ainsworth, C. H., and T. J. Pitcher. 2005. Using local ecological knowledge in ecosystem models. Pages 289-304 in G. H. Kruse, V. F. Gallucci, D. E. Hay, R. I. Perry, R. M. Peterman, T. C. Shirley, P. D. Spencer, B. Wilson, and D. Woodby, editors. Fisheries assessment and management in data-limited situations. Alaska Sea Grant College Program, University of Alaska Fairbanks, Fairbanks, Alaska, USA.

Ainsworth, C. H., T. J. Pitcher, and C. Rotinsulu. 2008. Evidence of fishery depletions and shifting cognitive baselines in Eastern Indonesia. Biological Conservation 141:848-859. http://dx.doi. org/10.1016/j.biocon.2008.01.006

Anadón, J. D., A. Giménez, R. Ballestar, and I. Pérez. 2009. Evaluation of local ecological knowledge as a method for collecting extensive data on animal abundance. Conservation Biology 23:617-625. http://dx.doi.org/10.1111/j.1523-1739.2008.01145. $\underline{x}$

Andrew, N. L., C. Béné, S. J. Hall, E. H. Allison, S. Heck, and B. D. Ratner. 2007. Diagnosis and management of small-scale fisheries in developing countries. Fish and Fisheries 8:227-240. http://dx.doi.org/10.1111/j.1467-2679.2007.00252.x

Baelde, P. 2003. Using fishers' knowledge goes beyond filling gaps in scientific knowledge - analysis of Australian experiences. Pages 78-86 in N. Haggan, C. Brignall, and L. Wood, editors. Putting Fishers' Knowledge to Work Conference Proceedings, August 27-30, 2001. Fisheries Centre Research Reports, Vol. 11(1), Fisheries Centre, University of British Columbia, Vancouver, British Columbia, Canada. 
Begossi, A. 2008. Local knowledge and training towards management. Environment, Development and Sustainability 10:591-603. http://dx.doi.org/10.1007/s10668-008-9150-7

Ben-Yami, M. 1964. Report on the fisheries in Ethiopia. Ministry of Foreign Affairs, Department for International Cooperation, Jerusalem, Israel.

Berkes, F., R. Mahon, P. McConney, R. Pollnac, and R. Pomeroy. 2001. Managing smallscale fisheries: alternative directions and methods. International Development Research Centre, Ottawa, Ontario, Canada.

Beverton, R. J. H., and S. J. Holt. 1957. On the dynamics of exploited fish populations. Chapman and Hall, London, UK.

Bradburn, N. M., L. J. Rips, and S. K. Shevell. 1987. Answering autobiographical questions: the impact of memory and inference on surveys. Science 236:157-161. http://dx.doi.org/10.1126/ science. 3563494

Bunce, M., L. D. Rodwell, R. Gibb, and L. Mee. 2008. Shifting baselines in fishers' perceptions of island reef fishery degradation. Ocean \& Coastal Management 51:285-302. http://dx.doi. org/10.1016/j.ocecoaman.2007.09.006

Bunce, L., P. Townsley, R. Pomeroy, and R. Pollnac. 2002. Socioeconomic manual for coral reef management. IUCN, The World Conservation Union, Gland, Switzerland.

Caddy, J. F., and J. A. Gulland. 1983. Historical patterns of fish stocks. Marine Policy 7:267-278. http://dx.doi.org/10.1016/0308-597X (83)90040-4

Campbell, G. 1993. The structure of trade in Madagascar, 1750-1810. International Journal of African Historical Studies 26:111-148. http://dx.doi.org/10.2307/219188

Chuenpagdee, R., and D. Pauly. 2008. Small is beautiful? A database approach for global assessment of small-scale fisheries: preliminary results and hypotheses. Pages 575-583 in J. Nielsen, J. J. Dodson, K. Friedland, T. R. Hamon, J. Musick, and E. Verspoor, editors. 4th World Fisheries Congress: Reconciling Fisheries with Conservation. American Fisheries Society, Vancouver, British Columbia, Canada.

Cortes, E., and J. A. Neer. 2006. Preliminary re-assessment of the validity of the $5 \%$ fin to carcass ratio for sharks. Collective Volume of Scientific Papers 59:1025-1036.

Daw, T. M. 2008. How fishers count: engaging with fishers' knowledge in fisheries science and management. Dissertation, Newcastle University, Newcastle upon Tyne, UK.

Daw, T. M. 2010. Shifting baselines and memory illusions: what should we worry about when inferring trends from resource user interviews? Animal Conservation 13:534-535. http://dx.doi. org/10.1111/j.1469-1795.2010.00418.x

Daw, T. M., J. Robinson, and N. A. J. Graham. 2011. Perceptions of trends in Seychelles artisanal trap fisheries: comparing catch monitoring, underwater visual census and fishers' knowledge. Environmental Conservation 38:75-88. http://dx.doi.org/10.1017/ $\underline{\mathrm{S} 0376892910000901}$

Fisheries Administration (FA). 2007. Fishery statistics of Sudan: based on the files of Fisheries Administration office in Port Sudan. FA, Khartoum, Sudan.
Fong, Q. 1999. Assessment of Hong Kong shark fin market: implication for fishery management. Dissertation, University of Rhode Island, Kingston, Rhode Island, USA.

Fowler, F. J., Jr. 2009. Survey research methods. Fourth edition. Sage, Thousand Oaks, California, USA.

Froese, R., and D. Pauly, editors. 2011. FishBase. [online] URL: www.fishbase.org

Garibaldi, L. 2012. The FAO global capture production database: a six-decade effort to catch the trend. Marine Policy 36:760-768. http://dx.doi.org/10.1016/j.marpol.2011.10.024

Haggan, N., B. Neis, and I. Baird, editors. 2007. Fishers' knowledge in fisheries science and management. UNESCO, Paris, France.

Harley, S. J., R. A. Myers, and A. Dunn. 2001. Is catch-per-uniteffort proportional to abundance? Canadian Journal of Fisheries and Aquatic Sciences 58:1760-1772. http://dx.doi.org/10.1139/ $\underline{\mathrm{f} 01-112}$

Henry, B., T. E. Moffitt, A. Caspi, J. Langley, and P. A. Silva. 1994. On the "remembrance of things past": a longitudinal evaluation of the retrospective method. Psychological Assessment 6:92-101. http://dx.doi.org/10.1037/1040-3590.6.2.92

Hilborn, R., and C. J. Walters. 1992. Quantitative fisheries stock assessment. Choice, dynamics and uncertainty. Chapman and Hall, New York, New York, USA. http://dx.doi.org/10.1007/978-1-4615-3598-0

Hind, E. J. 2012. Last of the hunters or the next scientists? Arguments for and against the inclusion of fishers and their knowledge in mainstream fisheries management. Dissertation, National University of Ireland, Galway, Ireland.

Holm, P. 2003. Crossing the border: on the relationship between science and fishermen's knowledge in a resource management context. Maritime Studies 2:5-33.

Huntington, H. P. 2000. Using traditional ecological knowledge in science: methods and applications. Ecological Applications 10:1270-1274. http://dx.doi.org/10.1890/1051-0761(2000)010[1270: UTEKIS]2.0.CO;2

Jentoft, S., B. J. McCay, and D. C. Wilson. 1998. Social theory and fisheries co-management. Marine Policy 22:423-436. http:// dx.doi.org/10.1016/S0308-597X(97)00040-7

Johannes, R. E. 1981. Words of the lagoon: fishing and marine lore in the Palau District of Micronesia. University of California Berkeley, Berkeley, California, USA.

Johannes, R. E., M. M. R. Freeman, and R. J. Hamilton. 2000. Ignore fishers' knowledge and miss the boat. Fish and Fisheries 1:257-271. http://dx.doi.org/10.1111/j.1467-2979.2000.00019.x

Koriat, A., M. Goldsmith, and A. Pansky. 2000. Toward a psychology of memory accuracy. Annual Review of Psychology 51:481-537. http://dx.doi.org/10.1146/annurev.psych.51.1.481

Lozano-Montes, H. M., T. J. Pitcher, and N. Haggan. 2008. Shifting environmental and cognitive baselines in the upper Gulf of California. Frontiers in Ecology and the Environment 6:75-80. http://dx.doi.org/10.1890/070056

Ludwig, D. 2001. The era of management is over. Ecosystems 4:758-764. http://dx.doi.org/10.1007/s10021-001-0044-x 
Mackinson, S. 2001. Integrating local and scientific knowledge: an example in fisheries science. Environmental Management 27:533-545.

Mackinson, S., and L. Nottestad. 1998. Points of view: combining local and scientific knowledge. Reviews in Fish Biology and Fisheries 8:481-490. http://dx.doi.org/10.1023/A\%3A1008847106984 http:// dx.doi.org/10.1023/A\%3A1008847106984

McCluskey, S. M., and R. L. Lewison. 2008. Quantifying fishing effort: a synthesis of current methods and their applications. Fish and Fisheries 9:188-200. http://dx.doi.org/10.1111/j.1467-2979.2008.00283. $\underline{\mathrm{x}}$

Means, B., and E. F. Loftus. 1991. When personal history repeats itself: decomposing memories for recurring events. Applied Cognitive Psychology 5:297-318. http://dx.doi.org/10.1002/ acp. 2350050402

Meliane, I. 2003. Shark finning: information paper. IUCN, Malaga, Spain.

Moody, M. F., and T. J. Pitcher. 2010. Eulachon (Thaleichthys pacificus): past and present. Fisheries Centre Research Reports, Vol. 18(2), Fisheries Centre, University of British Columbia, Vancouver, British Columbia, Canada.

Moore, J. E., T. M. Cox, R. L. Lewison, A. J. Read, R. Bjorkland, S. L. McDonald, L. B. Crowder, E. Aruna, I. Ayissi, P. Espeut, C. Joynson-Hicks, N. Pilcher, C. N. S. Poonian, B. Solarin, and J. Kiszka. 2010. An interview-based approach to assess marine mammal and sea turtle captures in artisanal fisheries. Biological Conservation 143:795-805. http://dx.doi.org/10.1016/j.biocon.2009.12.023

National Marine Fisheries Service (NMFS). 1993. Fishery management plan for sharks of the Atlantic Ocean. NMFS, U.S. Department of Commerce, Washington, D.C., USA.

Neis, B., D. C. Schneider, L. Felt, R. L. Haedrich, J. Fischer, and J. A. Hutchings. 1999. Fisheries assessment: what can be learned from interviewing resource users? Canadian Journal of Fisheries and Aquatic Sciences 56:1949-1963. http://dx.doi.org/10.1139/ $\underline{\mathrm{f} 99-115}$

O'Donnell, K. P., P. P. Molloy, and A. C. J. Vincent. 2012. Comparing fisher interviews, logbooks, and catch landings estimates of extraction rates in a small-scale fishery. Coastal Management 40:594-611. http://dx.doi.org/10.1080/08920753.2012.727734

O’Donnell, K. P., M. G. Pajaro, and A. C. J. Vincent. 2010. How does the accuracy of fisher knowledge affect seahorse conservation status? Animal Conservation 13:526-533. http://dx. doi.org/10.1111/j.1469-1795.2010.00377.x

Otero, J., F. Rocha, Á. F. González, J. Gracia, and Á. Guerra. 2005. Modelling artisanal coastal fisheries of Galicia (NW Spain) based on data obtained from fishers: the case of Octopus vulgaris. Scientia Marina 69:577-585.

Pauly, D. 1995. Anecdotes and the shifting baseline syndrome of fisheries. Trends in Ecology \& Evolution 10:430. http://dx.doi. org/10.1016/S0169-5347(00)89171-5

Pauly, D. 2006. Major trends in small-scale marine fisheries, with emphasis on developing countries, and some implications for the social sciences. Maritime Studies 4:7-22.
Pauly, D., and D. Zeller. 2003. The global fisheries crisis as a rationale for improving the FAO's database of fisheries statistics. Pages 1-9 in D. Zeller, S. Booth, E. Mohammed, and D. Pauly, editors. From Mexico to Brazil: Central Atlantic fisheries catch trends and ecosystem models. Fisheries Centre Research Reports, Vol. 11(6), Fisheries Centre, University of British Columbia, Vancouver, British Columbia, Canada.

Pitcher, T. J., R. Watson, R. Forrest, H. P. Valtýsson, and S. Guénette. 2002. Estimating illegal and unreported catches from marine ecosystems: a basis for change. Fish and Fisheries 3:317-339. http://dx.doi.org/10.1046/j.1467-2979.2002.00093.x

Rubin, D. C., and M. Kozin. 1984. Vivid memories. Cognition 16:81-95. http://dx.doi.org/10.1016/0010-0277(84)90037-4

Sáenz-Arroyo, A., C. M. Roberts, J. Torre, and M. Cariño-Olvera. $2005 a$. Using fishers' anecdotes, naturalists' observations and grey literature to reassess marine species at risk: the case of the Gulf grouper in the Gulf of California, Mexico. Fish and Fisheries 6:121-133. http://dx.doi.org/10.1111/j.1467-2979.2005.00185.x

Sáenz-Arroyo, A., C. M. Roberts, J. Torre, M. Cariño-Olvera, and R. R. Enríquez-Andrade. 2005b. Rapidly shifting environmental baselines among fishers of the Gulf of California. Proceedings of the Royal Society B: Biological Sciences 272:1957-1962. http://dx. doi.org/10.1098/rspb.2005.3175

Salmi, P. 1998. Towards sustainable vendace fisheries? Fishermen's conceptions about fisheries management. Boreal Environment Research 3:151-159.

Sankat, C. K., and S. Mujaffar. 2004. Sun and solar cabinet drying of salted shark fillets. Pages 1584-1591 in Proceeding of the 14th International Drying Symposium (IDS 2004). International Drying Symposium, São Paulo, Brazil.

Silvano, R. A. M., and J. Valbo-Jørgensen. 2008. Beyond fishermen's tales: contributions of fishers' local ecological knowledge to fish ecology and fisheries management. Environment, Development and Sustainability 10:657-675. http:// dx.doi.org/10.1007/s10668-008-9149-0

Silvert, W. L. 1981. Principles of ecosystem modelling. Pages 651-676 in A. R. Longhurst, editor. Analysis of marine ecosystems. Academic, New York, New York, USA.

Soto, C. G. 2006. Socio-cultural barriers to applying fishers' knowledge in fisheries management: an evaluation of literature cases. Dissertation, Simon Fraser University, Burnaby, British Columbia, Canada.

Teh, L., A. S. Cabanban, and U. R. Sumaila. 2005. The reef fisheries of Pulau Banggi, Sabah: a preliminary profile and assessment of ecological and socio-economic sustainability. Fisheries Research 76:359-367. http://dx.doi.org/10.1016/j. fishres.2005.07.009

Tesfamichael, D. 2001. Characterising the Eritrean artisanal fisheries using catch and effort data analysis. Thesis, Wageningen University, Wageningen, The Netherlands.

Tesfamichael, D. 2012. Assessment of the Red Sea ecosystem with emphasis on fisheries. Dissertation, University of British Columbia, Vancouver, British Columbia, Canada. 
Tesfamichael, D., and T. J. Pitcher. 2006. Multidisciplinary evaluation of the sustainability of Red Sea fisheries using Rapfish. Fisheries Research 78:227-235. http://dx.doi.org/10.1016/j. fishres.2006.01.005

Tesfamichael, D., and T. J. Pitcher. 2007. Estimating the unreported catch of Eritrean Red Sea fisheries. African Journal of Marine Science 29:55-63. http://dx.doi.org/10.2989/ AJMS.2007.29.1.5.70

Walley, C. J. 2002. 'They scorn us because we are uneducated': knowledge and power in a Tanzanian marine park. Ethnography 3:265-298. http://dx.doi.org/10.1177/146613802401092751

Wengraf, T. 2001. Qualitative research interviewing: semistructured, biographical and narrative methods. Sage, London, UK.

Worm, B., E. B. Barbier, N. Beaumont, J. E. Duffy, C. Folke, B. S. Halpern, J. B. C. Jackson, H. K. Lotze, F. Micheli, S. R. Palumbi, E. Sala, K. A. Selkoe, J. J. Stachowicz, and R. Watson. 2006. Impacts of biodiversity loss on ocean ecosystem services. Science 314:787-790. http://dx.doi.org/10.1126/science.1132294 
Appendix 1: Questionnaire to collect data on historical and present utilization of fishery resources.

\section{GENERAL BIO-DATA}

Code

Date

Location

1. Age/date of birth

2. Gender: $F \quad \square \quad M$

3. Place of birth Current place of residence

When did you move?

4. Occupation: Boat owner $\square \quad$ Skipper $\square \quad$ Crew $\square \quad$ Retired/when

Other

Did you change occupation? Yes

No

Do you do other jobs besides fishing?

Education (formal) level

How long have you been in fishing (start - end?)

How many generations has your family been in fishery? (Circle one) $1 \begin{array}{llllll}1 & 2 & 3 & 4 & >4\end{array}$

Number of family members involved in fishing?

Any interruption in your fishing career, when and for how long?

Interviewer's remarks 


\section{EFFORT DATA}

Code

Crew size

Boat: Type: Sambuk $\square \quad$ Huri $\square \quad$ Other

Size

Engine: Inboard $\square \quad$ Outboard $\square \quad$ HP

Gears: Gill net

Gill net dimensions

Mesh size

Average No. of nets used per setting:

Hook and line

No. of hooks per line?

Hook size

Do you use circle hooks: Yes

No

How many people are directly involved in handlining?

What bait do you use?

How do you get the bait?

How long, on average, did it take you to go to the fishing ground?

Present

Past

How long was a single trip (average or range in days?)

Anything else you would like to tell?

Interviewer's remarks 


\section{CATCH DATA}

Code

The best catch ever you recall:

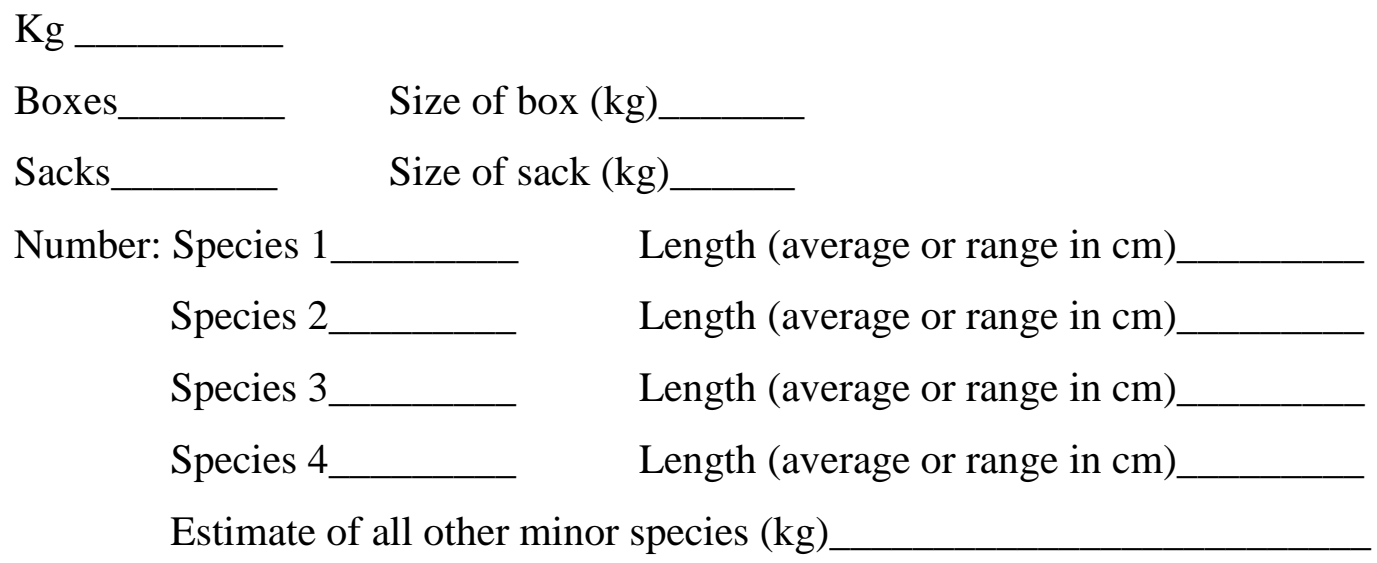

Other units

Size of largest fish ever caught $(\mathrm{cm})$ Species

Effort of best catch recalled:

Crew size: Trip length (days)

Average/typical catch rate when you started fishing

Average/typical catch rate at the moment (in the same unit as previous question)

Anything else you would like to tell?

Interviewer's remarks 